\title{
CFD Aerodynamic Analysis of Ahmed Body
}

\author{
Rehan Salahuddin Khan ${ }^{1}$, Sudhakar Umale ${ }^{2}$ \\ ${ }^{1}$ M.E. Student, Mechanical Engineering \\ ${ }^{2}$ Associate Professor in Mechanical Engineering \\ Sardar Patel College of Engineering \\ Mumbai-400058, Maharashtra, India.
}

\begin{abstract}
The CFD (Computational Fluid Dynamics) analysis is used to find the parameter in the automobile industry. This analysis is used to understand the fuel consumption, stability of the vehicle and passenger comfort. The air flow over ground vehicle is analysed and coefficient of drag is calculated using CFD (Ansys Fluent). For this calculation, Ahmed body (simplified car body) as ground vehicle is considered which is commonly used as test case in industry. The Ahmed body is made up of a round front part, a movable slant plane placed in the rear of the body to study the separation phenomena at $25^{\circ}$, $35^{\circ}$ angles, and a rectangular box, which connects the front and rear slant plane. The most significant feature of the body is the $25^{\circ}, 35^{\circ}$ angle of rear slant. Air is used as a working fluid. The inlet velocity of fluid is $40 \mathrm{~m} / \mathrm{s}$. $\mathrm{k}-\boldsymbol{\varepsilon}$ turbulent model used as a standard model. Two separate cases have been solved for two different front radius of Ahmed body R80, R120 and ground clearance at $20 \mathrm{~mm}, 40 \mathrm{~mm}$ and results are comparing. The results are present in the form of drag coefficient value and flow field which include velocity contour and velocity vector fields. the validation is carried out by simulation around the Ahmed body with the rear slant angle of $25^{0}, 35^{\circ}$.the actual wind tunnel experimental data are compared with the results.
\end{abstract}

Keywords - Aerodynamics, Ahmed body, k- $\varepsilon$ model, CFD, drag coefficient.

\section{INTRODUCTION}

\section{A. General}

The flow around road vehicle (car, buses, trucks) under normal operating condition is principally turbulent. It is typically characterized by large-scale separation and recirculation regions, a complex wake flow, long trailing vortices and interaction of boundary layer flow on vehicle and ground. In developing new road vehicle it is essential for the designer to understand thoroughly the structure of flow around the vehicle. This will have influence on such principal feature as the shape of vehicle, aerodynamic drag, fuel consumption, noise production and road handling. Traditionally, vehicle designer have gained their understanding of the air flow around a vehicle through extensive wind tunnel testing.

More recently (within last 10years), computational fluid dynamics (CFD) has matured sufficiently as a technology to enable it to calculate such quantities as drag and lift for a road vehicle without resort wind tunnel testing. However, the computational models are very large and even with state-ofthe-art processor it may take several day of CPU time to gain a solution. In order to reduce this to a time scale which is acceptable to vehicle designer (within a day),it is necessary to use a simplified computational technic and adopt a model to describe the mean effect of turbulence. Unfortunately, simple turbulence models often fail to calculate the flow properly e.g. the position of flow separation on rear slant is crucial in determining the aerodynamic drag but it is extremely difficult feature to calculate using a simple turbulence model. Hence, to road vehicle manufacturer, CFD is currently a subject to research rather than a design tool, and the key to understand vehicle aerodynamic is still the wind tunnel.

Road-vehicle aerodynamic design, vehicle attributes affected by aerodynamics, typical aerodynamic characteristics and method of calculating road-vehicle flows. A road-vehicle as being essentially a bluff body in very close ground proximity. The geometry of the vehicle is complex, the flow around it is fully three-dimensional, the boundary layers are turbulent, flow separation is common and there are large turbulent wakes in which longitudinal trailing vortices are common. As is typical for bluff bodies, the principal contribution to drag experienced by a road vehicle is pressure drag and major objective of vehicle aerodynamic design is the avoidance, reduction or control separation. Aerodynamicallyoptimized road vehicles still have a flow separation at the rear end. The vehicle's body can be truncated upstream of separation point without incurring a drag penalty. Air can be bled into the bluff body's wake to reduce drag. However, any benefit resulting from reduced drag must be offset against the power requirements of the bleed-air system. Viscous- inviscid flow interaction can be difficult to predict for any bluff body separated flow and this is particularly so when there is ground effects present. As the body is brought closer to the ground, flow around the body creates a down force (negative lift) which is controlled by the underbody flow. In contrast, the drag is almost independent of ground-distance as it is controlled by the outer flow.

\section{B. Aerodynamic Design of Ahmad Body}

Aerodynamics analysis is used in the design of car to reduce drag coefficient. The investigation has obtained the behaviour of newly developed turbulence models for complex geometry cases, a simplified car model, known as the Ahmed body, has been tested by Ahmed. The Ahmed body is made up of a round front part, a moveable slant plane placed at back part of the body to study the coefficient of drag and separation phenomena at different angles, and a rectangular box, which connects the front part and the rear slant plane. As the wake separation flow behind the Ahmed body is the main contributor to the drag force, accurate prediction of the separation process and the wake flow are the key to the successful modelling of this case. Many researchers [3, 9] 
have made use of CFD techniques to perform numerical simulations related to automobile. Several numerical simulations were performed to analyse the pressure field, velocity vector field, and aerodynamic force prediction related to a passenger car. The external surface of the car is very important in aerodynamics aspects of vehicles such as stability, comfort and fuel consumption at high speeds. The total weight and modification of the external surfaces of the car are the most important to improve the aerodynamics characteristics of the car [4-8]. These characteristics are helpful to improve the cruising conditions, greater stability of navigation, and lower fuel consumption. This is possible only when redesign of car and frame and use of electronic devices in the car. CFD Fluent software was used to study the K- $\varepsilon$ model to compute the flow properties around the car and its tail plates. Car drivers usually install tail plates that successfully reduce the drag and improve traction leading to better manoeuvre [3].

\section{Ahmed Turbulent Model}

The flow around vehicles is defined by highly turbulent, three-dimensional separations. There is a growing need for powerful numerical tools to analyse them. Computations (CFD) based on Reynolds-Averaged Navier Stokes Equations (RANS) are commonly used in automobile industry. Although they are very successful in predicting many parts of the flow around a vehicle at front, back, they are unable to predict unsteadiness in the wake region. The failure in predicting the base pressure is the major reason for the large disturbance in drag prediction between experiments and numerical simulations. To simulate the wake flow accurately, using Ahmed turbulence model is highly desirable [4 - 8].

\section{Importance of Wheel House in Ahmed Body}

The extensive improvements in aerodynamic design of car bodies have been investigated to reduce the aerodynamic drag coefficient. The aerodynamically unfavourable wheels are exposed to airflow of relatively high velocity. It has been observed by means of experimental investigations that the addition of wheels and wheelhouses to it leads to an increase of around $30 \%$ in drag, and $40 \%$ in lift, respectively. Another effect of the car body that influences significantly the drag caused by the wheels is its usually short longitudinal extension. This results in a strong impact of the frontal part of the vehicle on the direction of the flow of the wheels. The flow is characterized by a yaw angle with respect to the direction of the vehicle. If the distance between the front of the body and the wheel axis is decreasing the yaw angle of the flow increases. It has been found experimentally that the wheel space is very sensitive to the yaw angle of attack; it was seen that the drag coefficient of wheels in case of a yaw angle of $15^{\circ}$ is three-times the value at $0^{\circ}$ yaw angle. It was found that major part of the drag coefficient increase due to the addition of wheels and wheelhouses to a vehicle body is generated on the lower portion of the wheels which are exposed to the flow in the ground clearance of body. This lower portion of the wheels is very important source of large pressure forces together with the flow inside the wheelhouses, also has significant value on the overall flow field. Due to volume of the wheelhouses on the drag and lift on the vehicle body was investigated experimentally for a different geometry. It was found that drag and lift coefficients decreased almost linearly with the volume (around 10\%) compared to the drag increase due to wheels. The relatively different effect of the vehicle body shape onto the flow past the rotating wheels and in the wheelhouses of vehicle, now they are using Ahmed-body for the present investigations. The study on the effect of the wheels and wheelhouse to reduce the drag acting on them was carried out by means of RANS modelling. The Ahmed-body is a well-known simplified car body which has a rectangular shape with front rounded leading edges around its front face, straight side and trailing edges and slanted rear part which can be characterized mainly by its angle with respect to the top of the body and its extension. This body also provides a good basis for validation of numerical flow modelling against measurements. The Ahmed-body was investigated without wheelhouses and wheels in all previous literature on Ahmed body. Now a day due to CFD investigation become very easy in all over the field of automobile as it is steady or moving on the road. Due to simplicity of the geometry it has also a very advantageous in terms of relatively low Reynolds number dependency in the usual range for road vehicles. The features of the flow are governed mainly by the presence of the sharp edges of the geometry. At the present investigation, the slant angle of the rear part of the vehicle model was $25^{\circ}$. In this case there is a separation and reattachment phenomenon on the slanted region experienced from measurements. The Ahmed-body was modified by means of the addition of wheelhouses and wheels. The sizes of the wheels and the volume of the wheelhouses were determined by keeping the proportions of a conventional passenger car [12].

\section{EXPERIMENTAL DETAILS}

\section{A. Geometrical Dimension}

TABLE I

GEOMETRICAL DIMENSION [19]

\begin{tabular}{|l|l|}
\hline Tunnel size & $(2 \mathrm{~m} \times 1.46 \mathrm{~m}) 3 / 4$ open test section \\
\hline Length & $1.044 \mathrm{~m}$ \\
\hline Height & $0.288 \mathrm{~m}$ \\
\hline Front radius & $0.1 \mathrm{~m}$ \\
\hline Ground clearance & $0.05 \mathrm{~m}$ \\
\hline Slant angle & $25^{0}, 35^{0}$ \\
\hline Inlet velocity & $10,20,30,40 \mathrm{~m} / \mathrm{s}$ \\
\hline Yaw angle & $\mathrm{B}=0^{0}$ \\
\hline Blockage ratio & $3.8 \%$ \\
\hline Cross-sectional area & $\mathrm{A}=0.112 \mathrm{~m}^{0}$ \\
\hline
\end{tabular}

In this study simplified Ahmed vehicle body use for the experimentation. Measurement were made for two rear vehicle body slant angles $25^{\circ}$ and $35^{\circ}$ at a bulk air velocity of $40 \mathrm{~m} / \mathrm{s}$. Fig 2 show the experimental setup of Ahmed body used for experiment. Experimental specification of Ahmed body is shown in TABLE I. 


\section{B. Geometrical Details of Ahmed Body}

Ahmed body is simplified car model created by Ahmed et in 1980's to investigate the behaviour of newly developed turbulence models for complex geometry cases. The Ahmed body is made up of a round front part, a movable slant plane placed in the rear of the body to study the separation phenomena at different angles, and a rectangular box, which connects the front and rear slant plane as shown in figure 1.7. Ahmed body is simplified model of a car body, but it demonstrates all the flow features involved in an actual case of a moving car.

Current vehicle development needs strong background in aerodynamics to improve flow control by means of active or passive control devices. The complexity involved in the automobile design specially due to the great amount of accessories and devices that form its geometry makes the validation tasks unaffordable. The Ahmed model is a simple geometric body that retains the main flow features, specially the vortex wake flow where most part of the drag is concentrated and it is a good candidate to be used as a benchmark test.

The geometrical shape of the Ahmed body (simplified car body) investigated is depicted in Figure 1. Due to the considerable deviation of its geometry from normal vehicles, the body represents the basic aerodynamic properties of a vehicle, especially in the rear part. The rear slant angle $\phi$ has a strong effect on the aerodynamic drag and lift at the back. Both the drag and lift coefficients change abruptly at the angle $\phi=30^{\circ}$. Therefore, this angle is called the critical slant angle.

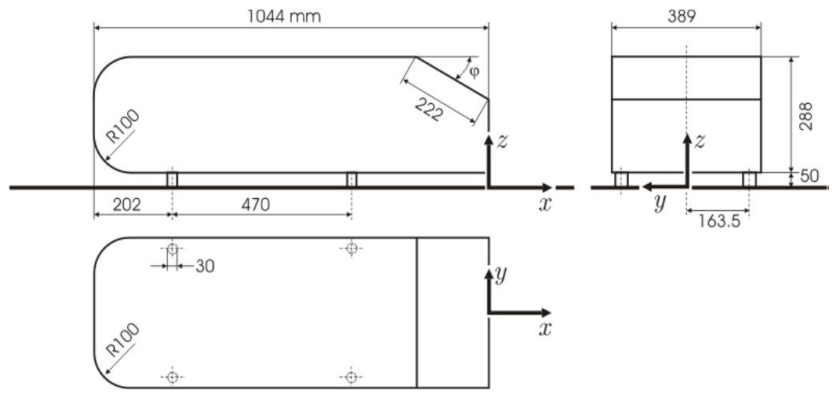

Fig. 1 Geometry of the Ahmed body [5]

The investigation effect of the rear slant angle by measurements at $\phi=25^{\circ}$ and $35^{\circ}$. For rear slant angles $\phi \leq$ $30^{\circ}$, an inward rotating pair of vortices with increasing strength is observed at back side of vehicles [4]. Therefore, the Ahmed body with the rear slant angle of $25^{\circ}$ belongs to the back side of vehicles, which exhibit very strong inward longitudinal vortices at the rear side. These vortices extend far into the wake region and generate a field of downwind in the enclosed region. At a slant angle of $30^{\circ}$, i.e., directly before transition to the full square back flow, this pair of vortices is developed most strongly, and the flow separates at the lower edge of the slant. This produces strong under pressures at that position, so that the aerodynamic drag reaches its maximum in this state [2].

\section{Experimental Method}

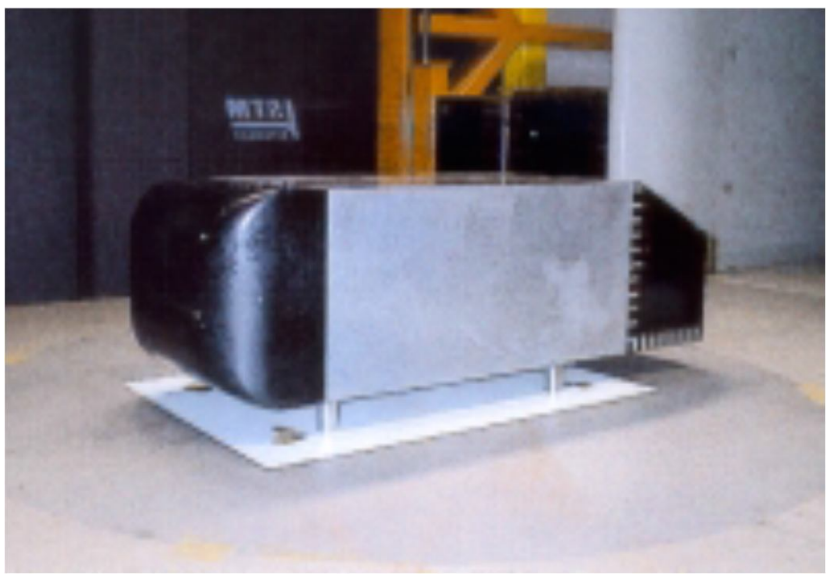

Fig. 2 Ahmed body mounted in the LSTM low-speed wind tunnel. [19]

The Ahmed body setup was mounted in the test section of the wind tunnel Figure 2. And detailed measurements of velocity profiles were made around this body. The experiments were performed in the low speed wind tunnel, a closed return facility which can be configured with an open or a closed test section. The present studies were conducted in a $3 / 4$ Open test section (i.e., floor, but no sides or ceiling) with a blockage ratio of $4 \%$. The wind Tunnel can generate flow velocities from 0 to $40 \mathrm{~m} / \mathrm{s}$ with average turbulence intensities of less than $0.25 \%$. All measurements to the Ahmed body were taken at bulk air velocities of $40 \mathrm{~m} / \mathrm{s}$. To conform continuity of the test section bulk velocity and air temperature, a computer-based feedback control system was utilised [19].

\section{NUMERICAL MODELING}

\section{A. Problem Definition}

In the present work, the 2D model of Ahmed body consist of inlet, outlet, nose, top bottom, slope, back, symmetry. Variation of coefficient of drag changes with rear slant angle is numerically investigated at $25^{\circ}$ and $35^{\circ}$. For further simplification change the front radius and ground clearance. Front radius as radius $80 \mathrm{~mm}$ and $120 \mathrm{~mm}$.and ground clearance at $20 \mathrm{~mm}$ and $40 \mathrm{~mm}$. Boundary parameter are fixed in accordance with experimental data [19]. Solver setup is specified to meet desirable simulating condition.

Different dimension of 2D car model (Ahmed body) are used for the analysis.

1. Rear Slant angle at 25 degree

2. Rear slant angle at 35 degree

3. Front radius at 80

4. Front radius at 120

5. Ground clearance at 20

6. Ground clearance at 40 


\section{B. Governing Equations}

The governing equation consists of continuity and momentum equation in the two dimension form with transient term as the flow is considered to be no steady state. The equations are as follows.

Continuity equation [5]:

$$
\frac{\partial u}{\partial x}+\frac{\partial v}{\partial y}=0
$$

Momentum equation in $\mathrm{X}$-direction [5]:

$$
\rho u \frac{\partial u}{\partial x}+\rho v \frac{\partial u}{\partial y}=-\frac{\partial \hat{p}}{\partial x}+\mu\left[\frac{\partial^{2} u}{\partial x^{2}}+\frac{\partial^{2} u}{\partial y^{2}}\right]
$$

Momentum equation in Y-direction [5]:

$$
\rho u \frac{\partial v}{\partial x}+\rho v \frac{\partial v}{\partial y}=-\frac{\partial \hat{p}}{\partial y}+\mu\left[\frac{\partial^{2} v}{\partial x^{2}}+\frac{\partial^{2} v}{\partial y^{2}}\right]
$$

\section{Boundary Condition}

For the car model boundary condition is applied at the inlet, outlet and the walls of the model.

- Inlet-velocity inlet

- Outlet-pressure outlet

- Wall condition-no slip and adiabatic wall condition

\section{Numerical Implementations}

Numerical implementation involves solver setting for the problem to be analysed. The solver used in the current analysis is FLUENT 14.5 in which 2D numerical modelling was done for transient state incompressible fluid flow.

\section{E. Geometrical Modeling}

The computational model of an experimentally tested 2D car model consists of inlet, outlet, nose, top, bottom, slope back, and symmetry is developed using ANSYS Workbench Design Modeler as per geometry parameters listed in Table I.

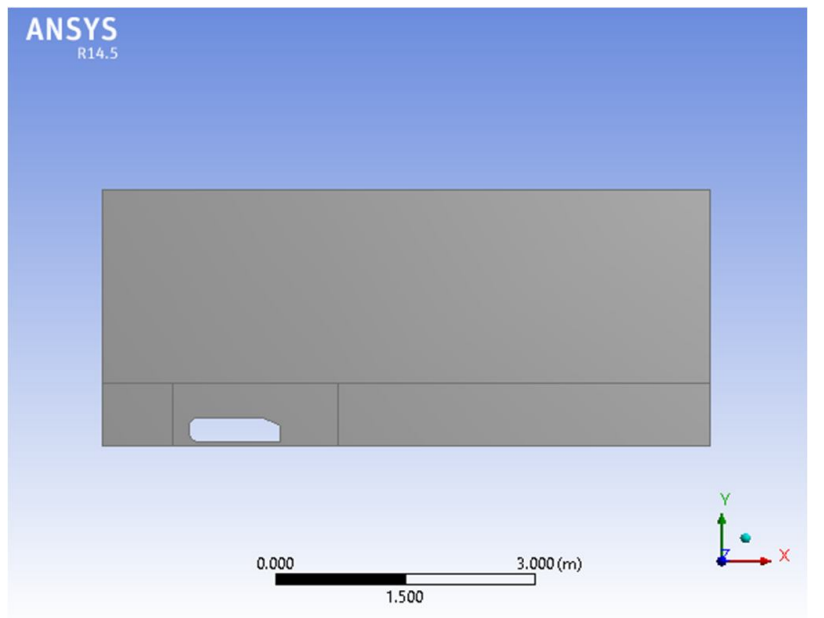

Fig. 3 Computational car model at rear slant angle $25^{\circ}$

As shown in Fig. 3 computational car model at rear slant angle at $25^{\circ}$, this is created in ansys fluent. The dimension of Ahmed body are $\mathrm{L}=1.044 \mathrm{~m}, \mathrm{~B}=0.389 \mathrm{~m}, \mathrm{H}=0.288 \mathrm{~m}$. The body is located $50 \mathrm{~mm}$ above ground level.

\section{F. Mesh Generation}

After physical modeling the domain is discretized with the help of meshing software ANSYS Workbench. Meshing software use different algorithms for different types of mesh generation. Patch conforming meshing technique is used to discretize the domain. The $2 \mathrm{D}$ computational domain is discretized which has triangular elements.

Grid independence tests are carried out to ensure that a nearly grid independent solution can be obtained. In the test, three different grid systems with 14252, 25207 \& 38323 elements are adopted for calculation of the whole Ahmed body and the differences in the overall pressure drop and the average heat transfer coefficient between last two grid systems are found around $2 \%$. Thus, considering both the computational time cost and solution precisions the second grid system is taken for the whole computation. Discretized model of Ahmed body is shown in the Fig. 4.

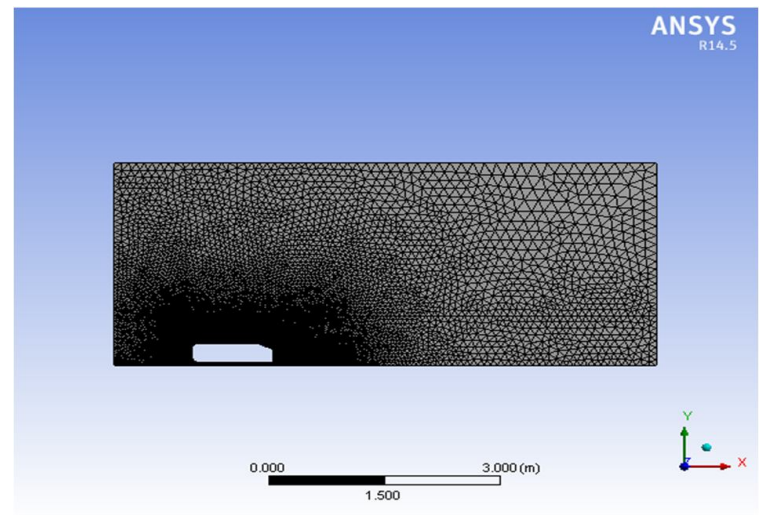

Fig. 4 Meshed model of car body

\section{G. Solver Setup}

For the present work the solver used was Fluent 14.5 Following are the steps taken for setting up the solving techniques in solver for 2D, steady state, incompressible flow using double precision and serial processing technique.

- Imports the meshed model created in Workbench and check the mesh.

- Scale the mesh as per the dimensions specified with appropriate scaling factor.

- The solver specifications such as pressure based, transient, planner and absolute velocity formulation are set.

- Defining models such as viscous model (standard k- $\varepsilon$ model) is done. A standard wall function is opted for near-wall treatment.

The model constants in $\mathrm{k}-\varepsilon$ equation are:

$\mathrm{C}_{\mu}=0.09$ (model constant for Turbulent viscosity)

$\mathrm{C}_{1 \varepsilon}=1.44$ (model constant for transport equation)

$\mathrm{C}_{2 \varepsilon}=1.92$ (model constant for transport equation)

$\sigma_{\mathrm{k}}=1.0 \quad$ (Turbulent kinetic energy Prandtl number)

$\sigma_{\varepsilon}=1.3$ (Turbulent dissipation rate Prandtl number) 


\section{Specifying properties:}

Fluid: Air

Density $(\rho)=1.225 \mathrm{~kg} / \mathrm{m}^{3}$

Viscosity $(\mu)=1.7894 \mathrm{e}-05 \mathrm{~kg} / \mathrm{ms}$

Solid: aluminium

Density $(\rho)=2719 \mathrm{~kg} / \mathrm{m}^{3}$

\section{Boundary Conditions:}

The Input boundary condition needed for the simulation has been taken from the experimental data presented by $\mathrm{H}$. Lienhart et al [19]. The boundary conditions applied to simulate the performance of Ahmed body at different dimensions are as follows:

-Inlet-velocity inlet

-Outlet-pressure outlet (atmospheric)

-Wall condition-no slip and adiabatic wall condition.

\section{Solution Methods:}

Pressure-Velocity Coupling:

Scheme-piso

skewness correction-1

neighbor correction-1

Spatial Discretization:

Gradient-green gauss cell based

Pressure-presto

Momentum-quick

Turbulent kinetic energy-quick

Turbulent dissipation rate-quick

Setting up Solution Controls and under relaxation factors: All flow, turbulent and energy equations are used for the solution.

Under Relaxation Factors:

Pressure $=0.7$

Density $=1.0$

Body Force $=1.0$

Momentum $=0.7$

Turbulence Kinetic energy $=0.7$

Initialize Solution: Solution is initialized from inlet region with set initial values.

Run calculation: Number of iterations is set to 1000 with reporting interval of 1 (each iteration).

\section{RSUlts AND Discussion}

\section{A. Validation of Simulated Results}

In order to validate simulation model, simulated results are compared with experimental results [19] in terms of coefficient of drag at corresponding rear slant angle at $25^{\circ}$ and $35^{0}$ with speed of $40 \mathrm{~m} / \mathrm{s}$ as shown in Fig. $5.1 \&$ 5.2[9].

\section{At rear slant angle $\mathbf{2 5}^{\circ}$}

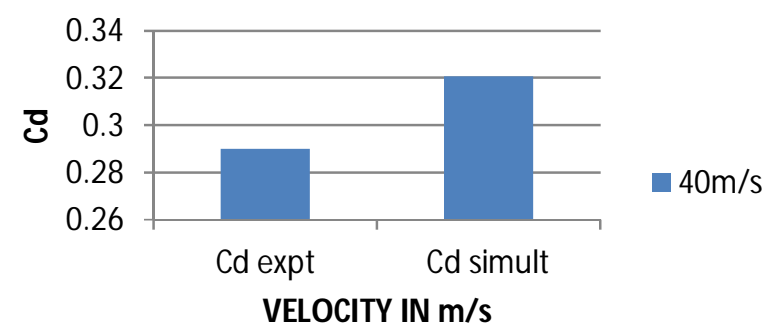

Fig. 5 Velocity v/s cd for experimental and simulation $25^{0}[9]$

It is observed that for rear slant angle at $25^{\circ}$ the overall coefficient of drag are in good agreement with the test data. Quantitatively, the maximum differences between numerical results and experimental data are around $1.073 \%$ for rear slant angle $25^{\circ}$. Apart from some unavoidable measurement errors, such discrepancies between experimental data and numerical results may be caused by the major simplification made in the computational model as such the effect of leakage flow was not taken into account in the simulation.

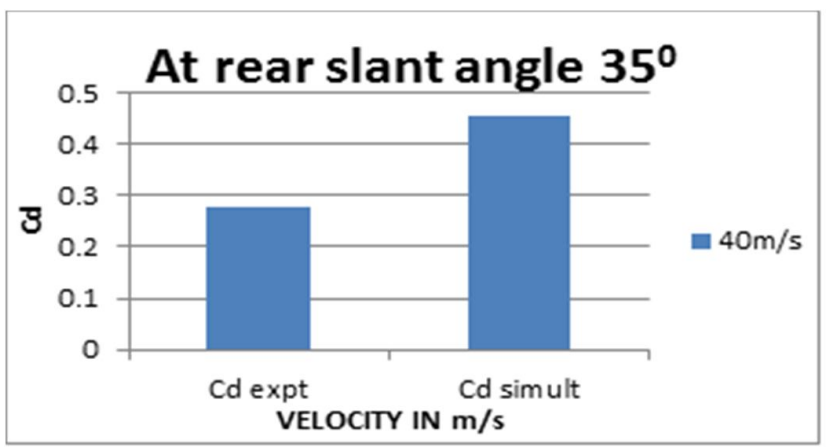

Fig. 6 Velocity v/s cd for experimental and simulation at $35^{0}[9]$

Results are obtained at $35^{\circ}$. A maximum difference between numerical and experimental data is around $1.703 \%$, reason for which is same as mentioned above.

\section{Velocity Contour for $\mathbf{2 5}^{0}$ :}

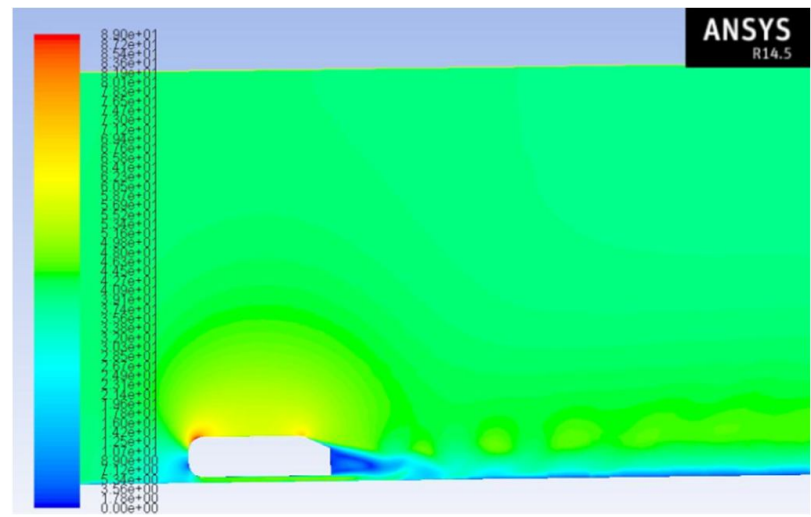

Fig. 7 Velocity contour for 2D Ahmed model with rear slant angle at $25^{\circ}$ 
For $25^{\circ}$ rears slant angle by using standard k-e model gives the result. Figure 7 indicates the velocity is almost zero at the nose of Ahmed body and the velocity is minimum at the rear slant side due to formation of vortices.

\section{Velocity Contour for $\mathbf{3 5}^{\circ}$}

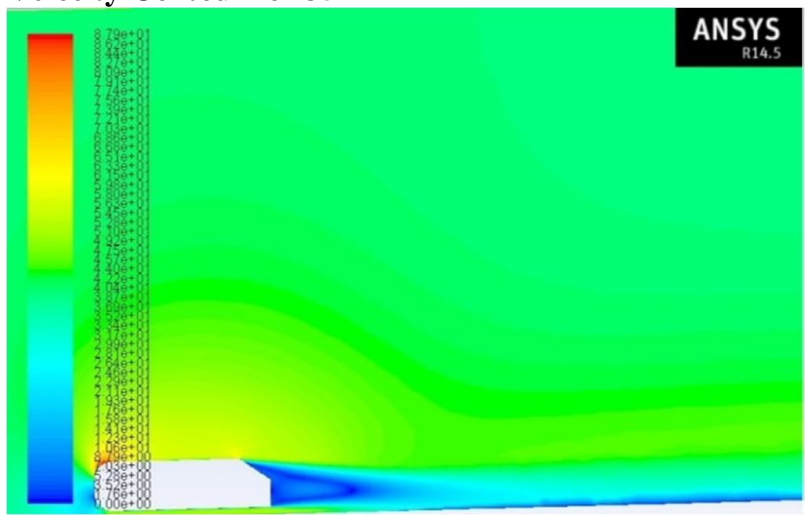

Fig. 8 Velocity contour for 2D Ahmed model with rear slant angle at $35^{\circ}$

For $35^{\circ}$ rear-slants angle by using standard k-e model gives the result. For the Ahmed body with $35^{\circ}$ rear-slant angle, Fig 8 show flow is fully separated over the slant and strong vortices do not form. Figure 8 indicates the velocity is almost zero at the nose of Ahmed body and the velocity is minimum at the rear slant side due to formation of vortices.

\section{B. Simulation of a new Ahmed body at front radius $80 \mathrm{~mm} \&$ $120 \mathrm{~mm}$}

In order to have better understanding of coefficient of drag on Ahmed body and to take advantage of simplified way of representing complicated geometrical domain and another configuration of Ahmed body with different front radius at $80 \mathrm{~mm}, 120 \mathrm{~mm}$ design is analysed. The simulation condition is shown in TABLE II.

TABLE II

SIMULATION CONDITION FOR DIFFERENT FRONT RADIUS CAR

\begin{tabular}{|l|l|}
\hline Length & $1.044 \mathrm{~m}$ \\
\hline Height & $0.288 \mathrm{~m}$ \\
\hline Front radius & $0.08 \mathrm{~m}, 0.12 \mathrm{~m}$ \\
\hline Ground clearance & $0.05 \mathrm{~m}$ \\
\hline Slant angle & $25^{0}$ \\
\hline Inlet velocity & $10,20,30,40 \mathrm{~m} / \mathrm{s}$ \\
\hline Yaw angle & $\mathrm{B}=0^{0}$ \\
\hline Blockage ratio & $3.8 \%$ \\
\hline Cross-sectional area & $\mathrm{A}=0.112 \mathrm{~m}^{2}$ \\
\hline
\end{tabular}

Development of computational model, grid generation, boundary conditions, cell zone conditions and solver setup are carried out in the same way as explained in previous chapters. Simulations were conducted for different front radius at $80 \mathrm{~mm}, 120 \mathrm{~mm}$ on speed of $40 \mathrm{~m} / \mathrm{s}$.

Simulated results obtained in terms of coefficient of drag at different front radius at corresponding velocity of air $40 \mathrm{~m} / \mathrm{s}$ as shown in Fig. 9

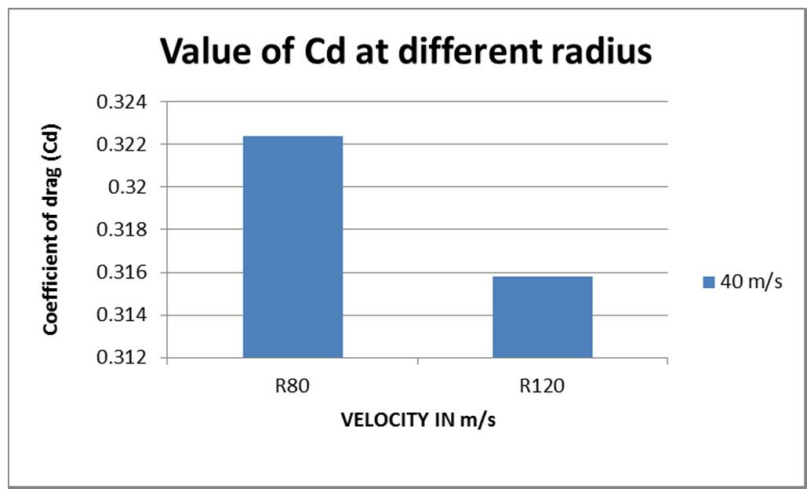

Fig. 9 Comparison of $\mathrm{Cd}$ values at different radius

After successful simulation of Ahmed body two front cases are tested on front radius at $80 \mathrm{~mm}$ and $120 \mathrm{~mm}$. to get optimum shape and working condition for low coefficient of drag. Now all the parameter is same as previous the changes takes only on front radius. Due to decrease in front radius as $80 \mathrm{~mm}$ there is all the effect and coefficient of drag almost same as validation part. But when increase the radius as $120 \mathrm{~mm}$ there is very high increase of coefficient of drag. So that by this simulation we can find out the optimum shape of Ahmed body. The wake separation is same as in validation part. There is no change take palace in wake region.

\section{Simulation of a new Ahmed body at ground clearance $20 \mathrm{~mm} \& 40 \mathrm{~mm}$}

In order to have better understanding of coefficient of drag on Ahmed body and to take advantage of simplified way of representing complicated geometrical domain and another configuration of Ahmed body with different ground clearance as $20 \mathrm{~mm}, 40 \mathrm{~mm}$ design is analysed. The simulation condition is shown in TABLE III.

TABLE III

SiMUlation CONDITION FOR DiFFERENT GROUND CLEARANCE OF CAR

\begin{tabular}{|l|l|}
\hline Length & $1.044 \mathrm{~m}$ \\
\hline Height & $0.288 \mathrm{~m}$ \\
\hline Front radius & $0.1 \mathrm{~m}$ \\
\hline Ground clearance & $0.02 \mathrm{~m}, 0.04 \mathrm{~m}$ \\
\hline Slant angle & $25^{0}$ \\
\hline Inlet velocity & $10,20,30,40 \mathrm{~m} / \mathrm{s}$ \\
\hline Yaw angle & $\mathrm{B}=0^{0}$ \\
\hline Blockage ratio & $3.8 \%$ \\
\hline Cross-sectional area & $\mathrm{A}=0.112 \mathrm{~m}^{0}$ \\
\hline
\end{tabular}

Development of computational model, grid generation, boundary conditions, cell zone conditions and solver setup are carried out in the same way as explained in previous chapters. Simulations were conducted for different ground clearance at $20 \mathrm{~mm}, 40 \mathrm{~mm}$ on speed of $40 \mathrm{~m} / \mathrm{s}$. 
Simulated results obtained in terms of coefficient of drag at different ground clearance at corresponding velocity of air 40 $\mathrm{m} / \mathrm{s}$ as shown in Fig. 10

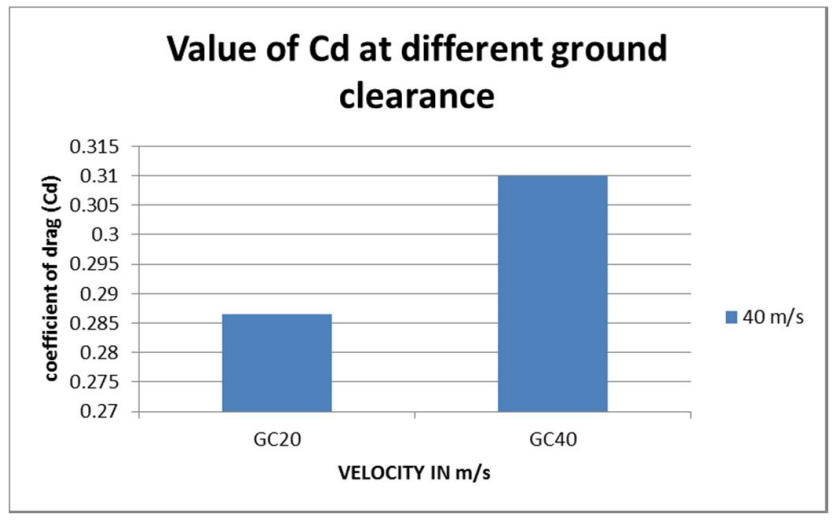

Fig. 10 Comparison of $\mathrm{Cd}$ values at ground clearance

After successful simulation of Ahmed body two ground clearance cases are tested on GC at $20 \mathrm{~mm}$ and $40 \mathrm{~mm}$ to get optimum working condition for low coefficient of drag. Now at $20 \mathrm{~mm}$ ground clearance we can see there is drop or decrease in coefficient of drag as compare to validation result so this is good for design point of view. We can also see there is increase of area of wake region and high air effect on lower nose side. For $40 \mathrm{~mm}$ ground clearance increase in coefficient of drag as compare to validation result other effect are same as $20 \mathrm{~mm}$ ground clearance. So that by this simulation we can find out the optimum ground clearance for Ahmed body.

Simulated results obtained in terms of net drag force at different front radius and ground clearance at corresponding velocity of air $40 \mathrm{~m} / \mathrm{s}$ as shown in Fig. 11

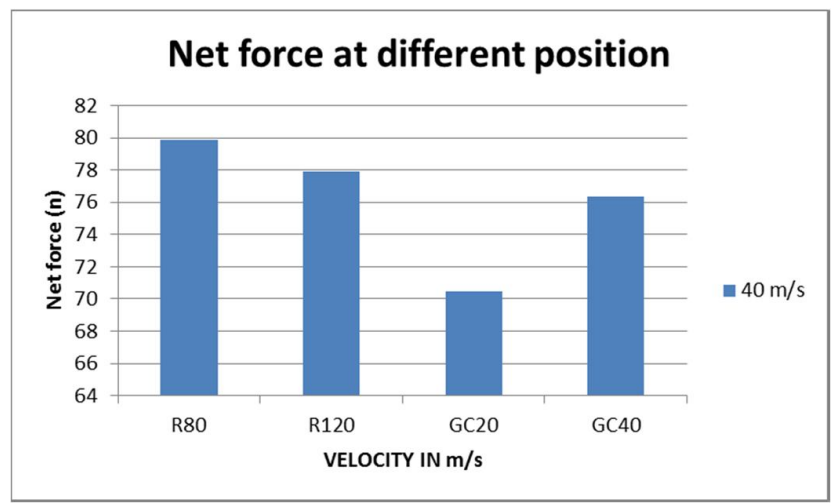

Fig. 11 Comparison of Net force at different position

After successful simulation of Ahmed body get net forces at different position and dimension. Above fig show the net force at different dimension and position at air velocity 40 $\mathrm{m} / \mathrm{s}$. we can compare the forces at different dimension and position and find out the optimum condition at which coefficient of drag is minimum.

\section{CONCLUSIONS}

- It was found that as radius decreases the coefficient of drag increases to $1.003 \%$ as compare to simulation result.

- It was found that as radius increases the coefficient of drag decreases to $0.9830 \%$ as compare to simulation result.

- For both the radius when increase and decrease there is strong longitudinal vortices are formed at the side edge of slant.

- It was found that as ground clearance decreases the coefficient of drag decreases to $0.89 \%$ as compare to simulation result.

- It was found that as ground clearance increases the coefficient of drag increases to $0.96 \%$ as compare to simulation result.

- For both the ground clearance when increase and decreases there is fully separated flow and without vortices formed.

- Wake region increases in vertical direction for ground clearance as compare to front radius .

\section{REFERENCES}

[1] Ahmed, S.R. and Ramm G., "Some salient features of the timeaveraged ground vehicle wake," SAE Technical Paper 840300, 1984.

[2] C. M. E. Robinson, "Advanced CFD modeling of road-vehicle aerodynamics," Phd. Thesis, University of Manchester Institute of Science and Technology, May 2001.

[3] R. B. Sharma and R. Bansal, "CFD simulation for flow over passenger car using tail plates for aerodynamic drag reduction," IOSR-JMCE, vol. 7(5), pp. 28-35, 2013.

[4] S. Yongling, W. Guangqiang and Xieshuo, "Numerical simulation of the external flow field around a bluff car," Shanghai Tongji University Shanghai, China

[5] C. Rajsinh B. and T. K. Raj R. "Numerical investigation of external flow around the ahmed reference body using computational fluid dynamics," Research Journal of Recent Sciences, vol. 1(9), pp. 1-5, 2012.

[6] D. Y Dhande, "Experimental analysis of aerodynamic aspects of sport utility vehicle," IJEST, vol. 5(7), pp. 1476-1480, 2013.

[7] M. Desai, S. A. Channiwala and H. J. Nagarsheth, "A Comparative assessment of two experimental methods for aerodynamics performance evaluation of car," Journal of scientific and industrial Research, vol. 67, pp. 518-522, 2008.

[8] A. I. Heft, T. Indinger and N. A. Adams, "Introduction of a new realistic generic car model for aerodynamic investigations," $S A E$ International, 2012.

[9] W. Meile, G. Brenn, A. Reppenhagen, B. Lechner and A. Fuchs, "Experiments and numerical simulations on the aerodynamics of the Ahmed body," ISSR, vol. 3(1), pp. 32-39, 2011.

[10] R. Bansal1 and R. B. Sharma, "Drag reduction of a generic passenger car using vortex generator with different yaw angles," International Journal of Automobile Engineering Research and Development, vol. 3, pp. 73-80, 2013.

[11] T. Regert, and Tamas Lajos, "Investigation of simple possibilities for reduction of drag due to the wheels of road vehicles," EASC, 2009.

[12] N. E.Ahmed and E.Abo-serie and A.Gaylerd, "Mesh optimization for ground vehicle aerodynamics," ISSRES, vol. 2(1), pp. 54-65, 2010.

[13] C. Lai, Y. Kohama, S. Obayashi, S. Jeong, "Experimental and numerical investigation on the influence of vehicle rear diffuser angle on aerodynamics drag and wake structure," International Journal of Automotive Engg., vol. 2, pp. 47-53, 2011.

[14] G. Franck and Jorge D'El'1a, "CFD modeling of the flow around the Ahmed vehicle model," pp. 1-4. 
[15] D. P. Menon, S. Kamat, G. Yangnavalkya, S. Mukkamala and P. S. Kulkarni, "To improve the aerodynamic performance of amodel hatchback car with the addition of a rear roof spoiler," 16th Annual CFD Symposium, August 2014.

[16] X. HU, Rui ZHANG, Jian YE, Xu YAN and Zhiming ZHO, "Influence of different diffuser angle on sedan's aerodynamic characteristics," vol. 22, pp. $239-245,2011$.

[17] M. Khaled, HichamElHage , FabienHarambat , H. Peerhossaini, "Some innovative concepts for car drag reduction: A parametric analysis of aerodynamic forces on a simplified body," Elsevier, vol. 107, pp. 3647, 2012.

[18] D. K. Kalyan and A.R. Paul, "Computational study of flow around a simplified 2D ahmed body," IJESIT, vol. 2(3), pp. 148-153, 2013.

[19] H. Lienhart, C. Stoots and S. Becker, Flow and turbulence structures in the wake of a simplified car model (Ahmed Model).

[20] www.CFD-online.com 